\title{
Corrigendum: Regional copy number-independent deregulation of transcription in cancer
}

Nicolas Stransky, Céline Vallot, Fabien Reyal, Isabelle Bernard-Pierrot, Sixtina Gil Diez de Medina, Rick Segraves, Yann de Rycke, Paul Elvin, Andrew Cassidy, Carolyn Spraggon, Alexander Graham, Jennifer Southgate, Bernard Asselain, Yves Allory, Claude C Abbou, Donna G Albertson, Jean Paul Thiery, Dominique K Chopin, Daniel Pinkel \& François Radvanyi

Nature Genetics 38, 1386-1396 (2006); published online 12 November 2006; corrected after print 27 February 2008

In the version of this article initially published, the horizontal dashed lines representing the threshold value in the panels in row $\mathrm{b}$ of Figures 2 and 4 were incorrectly placed. The errors have been corrected in the HTML and PDF versions of this article. See below for the corrected version of the figures.

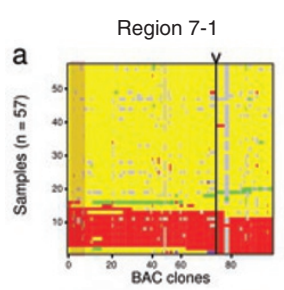

Probe set position (Mb)

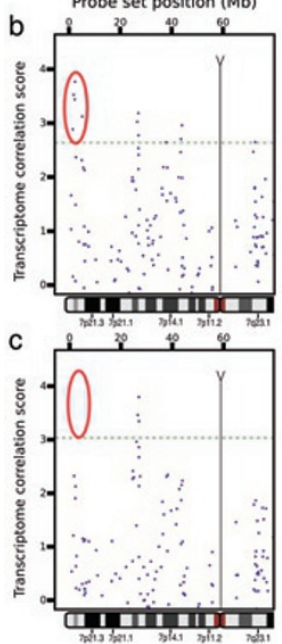

Region 8-1

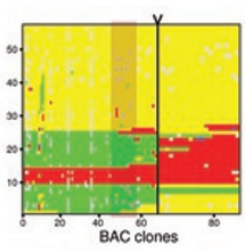

Probe set position (Mb)

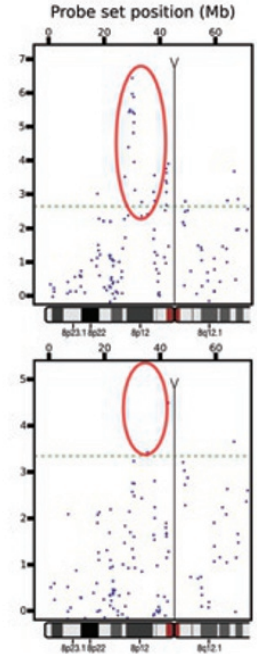

Figure 2
Region 10-4

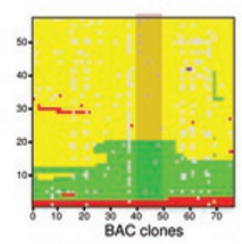

Probe set position (Mb)

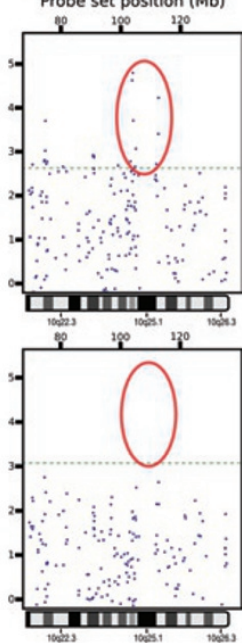

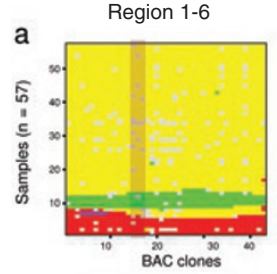

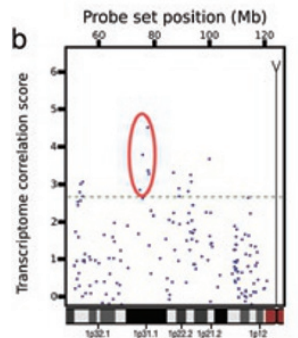

C

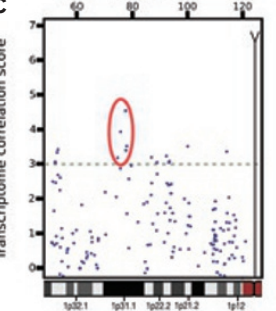

Region 5-3

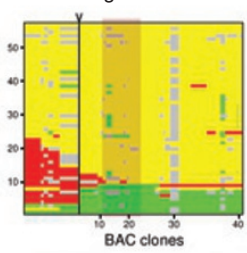

Probe set position (Mb)
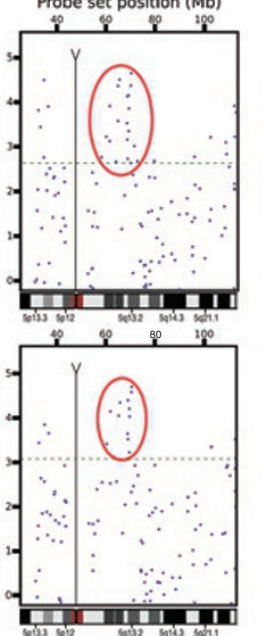

Figure 4

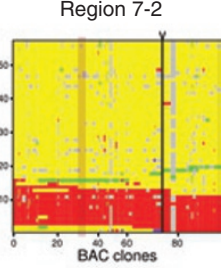

Probe set position (Mb)
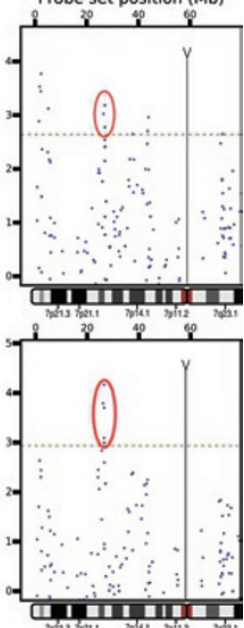

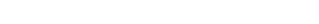

. 